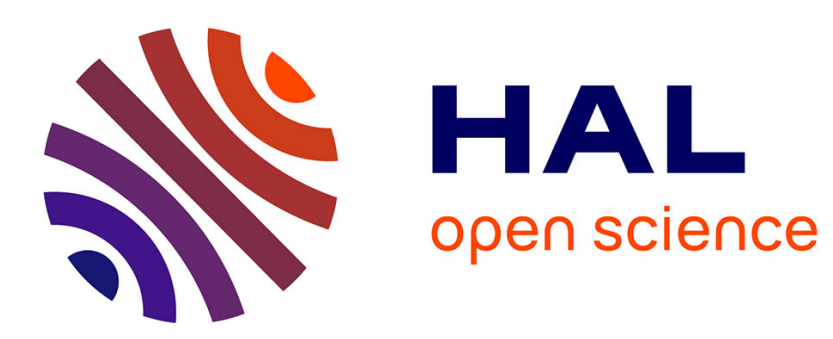

\title{
Control of salinity on the mixed layer depth in the world ocean. Part I: General description
}

Clément de Boyer Montégut, Juliette Mignot, Alban Lazar, Sophie Cravatte

\section{To cite this version:}

Clément de Boyer Montégut, Juliette Mignot, Alban Lazar, Sophie Cravatte. Control of salinity on the mixed layer depth in the world ocean. Part I: General description. Journal of Geophysical Research. Oceans, 2007, 112 (C6), pp.C06010. 10.1029/2006JC003953 . hal-00164665

\section{HAL Id: hal-00164665 https://hal.science/hal-00164665}

Submitted on 6 Jan 2022

HAL is a multi-disciplinary open access archive for the deposit and dissemination of scientific research documents, whether they are published or not. The documents may come from teaching and research institutions in France or abroad, or from public or private research centers.
L'archive ouverte pluridisciplinaire HAL, est destinée au dépôt et à la diffusion de documents scientifiques de niveau recherche, publiés ou non, émanant des établissements d'enseignement et de recherche français ou étrangers, des laboratoires publics ou privés. 


\section{Control of salinity on the mixed layer depth in the world ocean: \\ 1. General description}

Clément de Boyer Montégut, ${ }^{1}$ Juliette Mignot, ${ }^{2}$ Alban Lazar, ${ }^{2}$ and Sophie Cravatte ${ }^{3}$

Received 6 October 2006; revised 11 January 2007; accepted 26 January 2007; published 19 June 2007.

[1] Using instantaneous temperature and salinity profiles, including recent Argo data, a global ocean climatology of monthly mean properties of the "barrier layer" (BL) phenomenon is constructed. This climatology is based on the individual analysis of instantaneous profiles in contrast with previous large-scale climatologies derived from gridded fields. This ensures a more accurate description of the BL phenomenon. We distinguish three types of regions: BLs are quasi-permanent in the equatorial and western tropical Atlantic and Pacific, the Bay of Bengal, the eastern equatorial Indian Ocean, the Labrador Sea, and parts of the Arctic and Southern Ocean. In the northern subpolar basins, the southern Indian Ocean, and the Arabian Sea, BLs are rather seasonal. Finally, BLs are typically never detected between $25^{\circ}$ and $45^{\circ}$ latitude in each basin. Away from the deep tropics, the analysis reveals strong similarities between the two hemispheres and the three oceans regarding BL seasonality and formation mechanisms. Temperature inversions below the mixed layer are often associated with BLs. Their typical amplitude, depth, and seasonality are described here for the first time at global scale. We suggest that this global product could be used as a reference for future studies and to validate the representation of upper oceanic layers by general circulation models.

Citation: de Boyer Montégut, C., J. Mignot, A. Lazar, and S. Cravatte (2007), Control of salinity on the mixed layer depth in the world ocean: 1. General description, J. Geophys. Res., 112, C06011, doi:10.1029/2006JC003953.

\section{Introduction}

[2] Classically, the vertical structure of the upper ocean can be schematically divided into two layers: a near surface layer where temperature and salinity are well mixed and the deeper stratified ocean. The near-surface mixed layer is the site of active air-sea interaction. The transfer of mass, momentum, and energy between the atmosphere and this homogeneous layer is the source of most oceanic motions and at short timescales (a day or a few days), its thickness determines the thermal and mechanical inertia of the upper ocean. In a stable ocean, water density is minimum in this layer. It is separated from the ocean interior by a strong vertical density gradient, also called pycnocline.

[3] Definitions of the mixed layer depth are most commonly based on a stratification criteria: the base of the mixed layer is usually defined as the top of the pycnocline, being the depth where the density has increased by a certain

\footnotetext{
${ }^{1}$ Frontier Research Center for Global Change, Japan Agency for Marine-Earth Science and Technology, Yokohama, Japan.

${ }^{2}$ Laboratoire d'Océanographie et du Climat: Expérimentations et Approches Numériques, Institut Pierre Simon Laplace, Unité Mixte de Recherche, CNRS/IRD/UPMC, Paris, France.

${ }^{3}$ Laboratoire d'Etudes en Géophysique et Océanographie Spatiales, Unité Mixte de Recherche, CNRS/IRD/CNES/Université Paul Sabatier, Toulouse, France.

Copyright 2007 by the American Geophysical Union. 0148-0227/07/2006JC003953
}

threshold from its surface value. In practice, given the lack of salinity data, scientists have often concentrated on the temperature stratification, assuming that the top of the thermocline and halocline have the same depth and thus together define that of the pycnocline. However, this view is simplified and in the real ocean, the situation is frequently different, as a result of specific thermal and haline forcings. Situations where the top of the halocline is shallower than that of the thermocline have been observed since the 1960s [Defant, 1961; Rotschi et al., 1972; Lukas and Lindstrom, 1987; Lindstrom et al., 1987] and baptized the "barrier layer" phenomenon at the end of the 1980s [Godfrey and Lindstrom, 1989]. Instead of two, the vertical structure of the upper ocean is then divided into three layers (Figure 1): the mixed layer, limited by the top of the halocline (that defines the top of the pycnocline in that case), the so-called barrier layer (BL), confined between the top of the halocline and of the thermocline, and the deep ocean. Schematically, the temperature in the $\mathrm{BL}$ is constant and equal to that in the mixed layer (Figure 1a). In some cases, however, the salinity stratification is such that the stability of the ocean can even support a temperature increase in subsurface [e.g., Shankar et al., 2004]. The latter then reaches a subsurface maximum within the BL before decreasing again at greater depth (Figure 1b).

[4] BLs (associated with a subsurface temperature inversion or not) have important consequences on the air-sea 
(a)

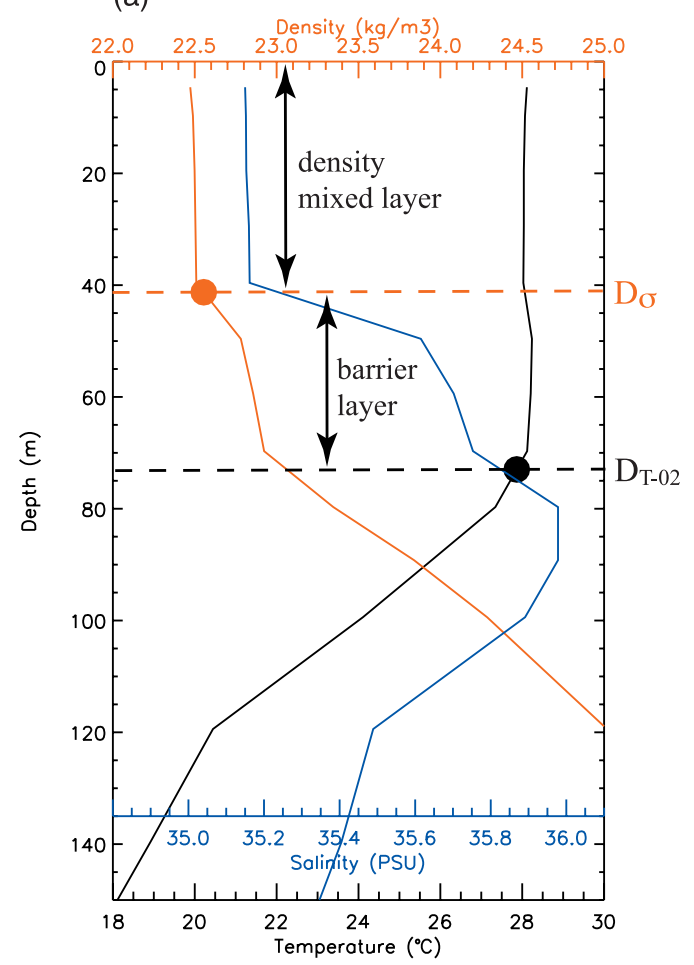

(b)

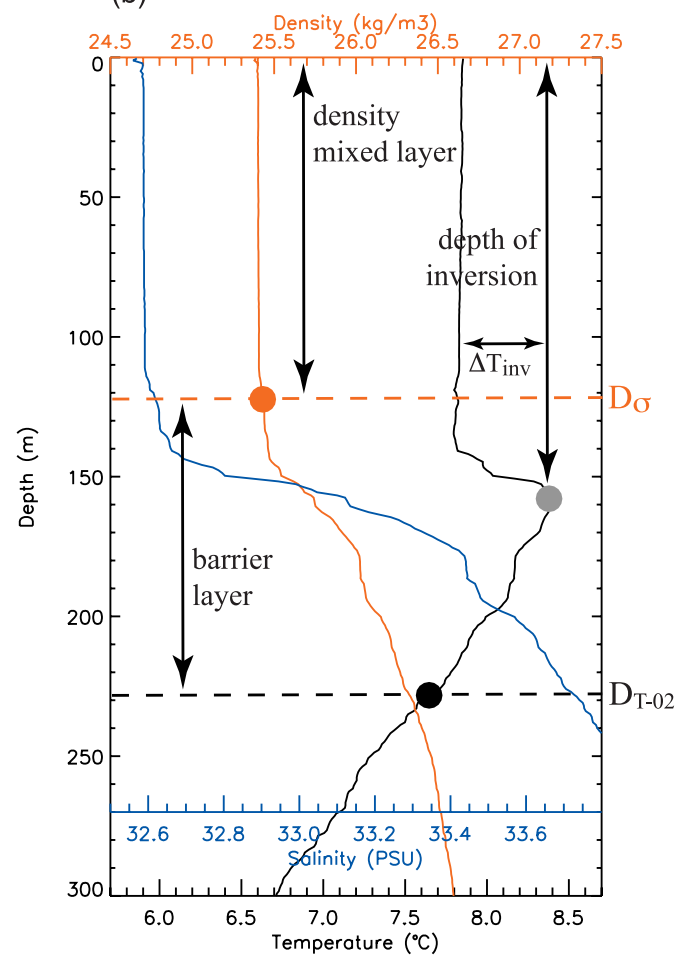

Figure 1. Examples of profiles where salinity controls the depth of the mixed layer. Temperature (black), salinity (blue), and density (red) profiles are measured (a) from an Argo float on 31 January 2002 in the southeastern Arabian Sea $\left(67.3^{\circ} \mathrm{E}, 7.4^{\circ} \mathrm{N}\right)$ and (b) from a CTD probe on 21 February 1999 in the northeastern Pacific Basin $\left(136.3^{\circ} \mathrm{W}, 47.7^{\circ} \mathrm{N}\right)$. Note the different vertical and horizontal scales used for the two profiles. The red solid dot shows the depth where the density criteria is reached, thus defining $D_{\sigma}$ (see text). The black solid dot shows the depth where the temperature criteria is reached, thus defining $D_{T-02}$ (see text). $D \sigma$ and $D_{T-02}$ limit the barrier layer (BL). Figure 1a is an example of classic BL case, where the temperature is approximately homogeneous below the density mixed layer. Figure $1 \mathrm{~b}$ is an example of vertical temperature inversion (section 3.2). The grey solid dot shows the depth of the maximum temperature inversion below the mixed layer. The amplitude of the inversion as compared to the surface (10 $\mathrm{m}$ depth reference level) is indicated by $\Delta T_{i n v}$

interactions and important potential climatic impact. When they occur, the energy transferred from the atmosphere to the ocean by wind and buoyancy forcing is trapped in the upper mixed layer limited by the salt stratification, which is thinner and thus more reactive than the one defined by the temperature mixed layer [Vialard and Delecluse, 1998a]. Vialard and Delecluse [1998a] also showed that the BL could protect the surface layer from heat exchanges with the thermocline and thus inhibit the surface cooling. Furthermore, the warm reservoir below the upper mixed layer associated to a classical $\mathrm{BL}$ or an inversed temperature profile can potentially be eroded by intense atmospheric forcing and thus induce a positive sea surface temperature anomaly that was suggested to significantly influence the onset of El Niño-Southern Oscillation (ENSO) events [e.g., Maes et al., 2002; Maes et al., 2004] or the development of the Indian monsoon [Masson et al., 2005], the Madden Julian Oscillation, and tropical cyclones.

[5] It is both because the mixed layer is relatively shallow and can thus be eroded relatively easily and because oceanatmosphere coupling is strongest at low latitudes that studies of the BL have mainly focused on the tropical oceans. Recently, however, Kara et al. [2000] pointed out the existence of thick BLs in the subpolar North Pacific. Furthermore, several studies showed the importance of salinity in controlling the stratification and the mixed layer depth in the middle to high latitudes [e.g., Reverdin et al., 1997].

[6] In spite of this possible global occurrence of the potential climatic impacts and of the fundamental importance of correctly diagnosing the upper ocean heat budget, global seasonal maps of the differences between the upper density and temperature stratification have, to our knowledge, only been presented twice. Tomczak and Godfrey [1994] presented global maps for two seasons, winter and summer, using the Levitus [1982] world ocean data set. Monterey and Levitus [1997] subsequently showed maps based on the more recent Levitus and Boyer [1994] World Ocean Atlas. In addition, we have to mention the milestone analysis of Sprintall and Tomczak [1992] dedicated to the tropical areas. These previous studies greatly contributed to the knowledge and understanding of global BL climatology. Yet, primarily because of the lack of data, they were all based on already averaged and interpolated data sets. This approach results in smoothed vertical profiles and can thus create artificial mixing of water masses. It can also introduce biases in estimating subsurface quantities such as 
(a) temperature/salinity profiles 1967-2006
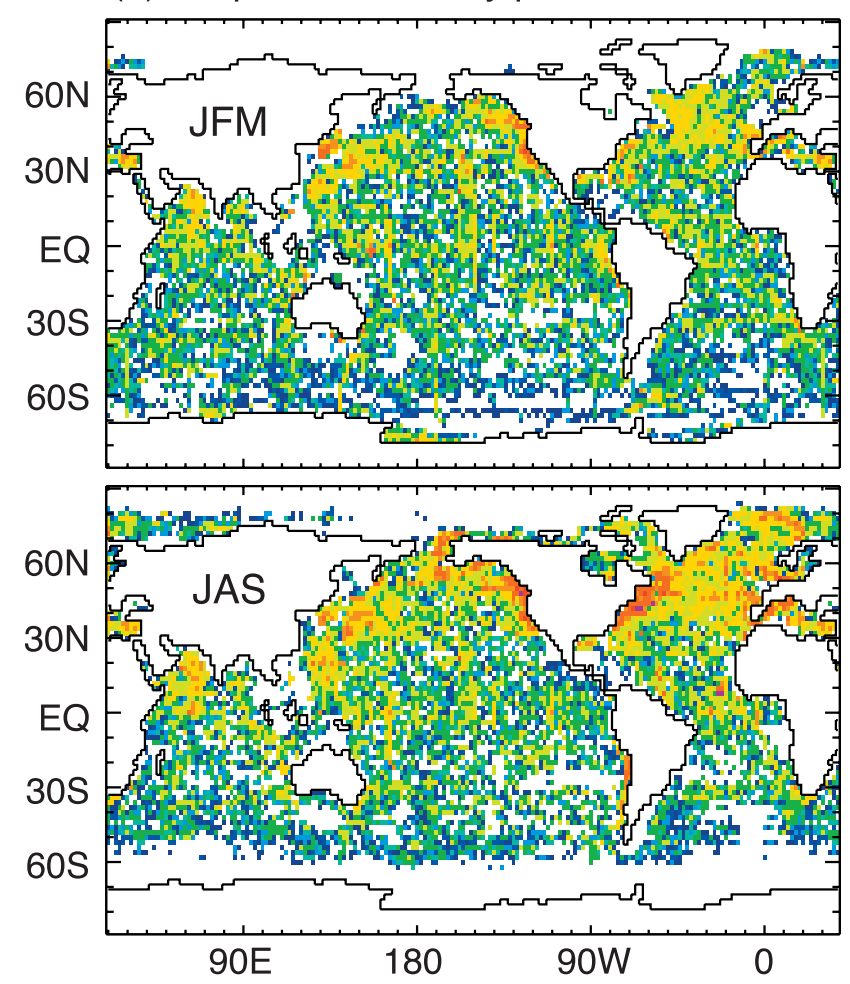

(b) temperature profiles 1967-2006
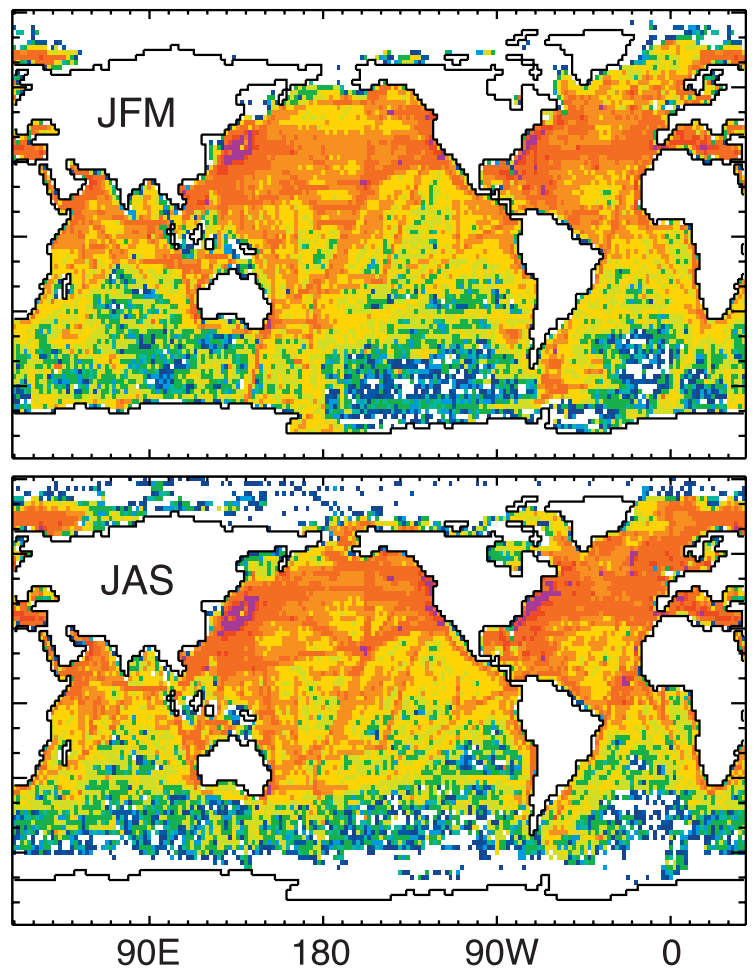

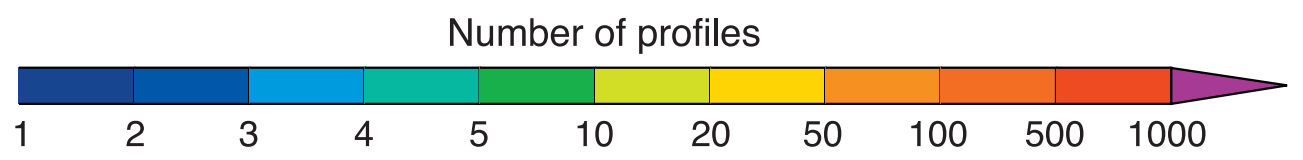

Figure 2. Distribution of profiles in each $2^{\circ}$ by $2^{\circ}$ mesh box. (a) Profiles with both temperature and salinity data, used to compute the barrier layer thickness (BLT) climatology (Figure 3). (b) Profiles with temperature data used to build the temperature inversion maps (Figure 6). Data are taken from the National Oceanographic Data Center, World Ocean Circulation Experiment, and Argo database between 1967 (first year with CTD salinity profiles) and 2006. JFM and JAS indicate the two seasons JanuaryFebruary-March and July-August-September, respectively.

barrier layer thickness (BLT) or mixed layer depth [de Boyer Montégut et al., 2004]. More recently, other authors have used individual profiles, thereby retaining more detailed structures, but their studies only concerned limited area [e.g., Ando and McPhaden, 1997; Sato et al., 2004; Qu and Meyers, 2005]. Here, we present for the first time a global climatology of the differences between the upper density and temperature stratification based on the analysis of most of the available instantaneous profiles of the upper ocean. Our aim is to give a global insight into the occurrence, seasonality, and order of magnitude of these differences and thus to better document and understand the control of the mixed layer by salinity in the world ocean. Our objective is also to present a new global product that we believe is of high interest for model validations and improvements or studies of the upper ocean budgets. Our product shows that the control of the mixed layer by salinity is a global phenomenon, primarily at play in winter.

[7] The data set and methodology is presented in the following section. Global maps documenting the seasons and areas where the salinity has a substantial influence on the vertical stratification of the upper ocean are described in section 3. Temperature inversions below the mixed layer will also be introduced in that section, and BL criteria will be discussed in light of these results. Section 4 focuses on the subpolar and polar regions, where large temperature inversions are detected, while a companion paper [Mignot et $a l ., 2007]$ is entirely dedicated to the tropical areas. Conclusions are given in section 5 .

\section{Data Set and Method}

\subsection{Data Set}

[8] This study is based on the collection of more than 500,000 instantaneous temperature and salinity profiles collected between 1967 and 2002 and obtained from the National Oceanographic Data Center (NODC) and from the World Ocean Circulation Experiment (WOCE) database, complemented by those available between 1996 and January 2006 from the Argo Global Data Centers (GDAC). The first two databases were used by de Boyer Montégut et al. [2004] to construct a new global mixed layer depth climatology. The global array of profiling floats, Argo, returning now around 100,000 profiles of temperature and salinity per year is the greatest source of observations for ocean subsurface. It represents approximately $30 \%$ of the total amount of profiles 
we use in this study. The seasonal spatial distributions of the data are shown in Figure 2. Figure 2a can be compared with Figure 1b of de Boyer Montégut et al. [2004] which represents the temperature-salinity profiles distribution without Argo database. A striking improvement is the reduction of the sparsity of salinity data in every oceans and especially in the Southern Ocean. Even if some areas have a short temporal coverage with a likely trend toward the recent years, such a distribution now allows us to construct a reliable monthly climatology of subsurface ocean variables (e.g., mixed layer depth, BLT. . .) based on both temperature and salinity observations.

[9] Additionally, we also used Expendable Bathythermograph (XBT) and Mechanical Bathythermograph (MBT) temperature profiles from NODC when investigating the occurrence of temperature inversions below the mixed layer (cf. section 3.2). Figure 2b shows the distribution of all temperature profiles available between 1967 and 2006. Even if the benefits of adding Argo data is less impressive than with salinity data, it still represents a considerable improvement in coverage of the southern part of the three oceans.

[10] The reader is referred to de Boyer Montégut et al. [2004] for a detailed description of the data analysis. The average vertical resolution of the profiles are $8.2 \mathrm{~m}, 2.3 \mathrm{~m}$, $19.5 \mathrm{~m}, 9.4 \mathrm{~m}$, and $10.5 \mathrm{~m}$ for profiling floats (PFL), conductivity-temperature-depth (CTD), XBT, MBT, and Argo profilers respectively.

\subsection{Methodology}

[11] As in the work of de Boyer Montégut et al. [2004], the $2^{\circ}$ spatial resolution climatology described below is based on direct estimates of the temperature and density stratification from individual profiles with data at observed levels. This is a different and better approach from the one based on averaged profiles [Tomczak and Godfrey, 1994; Monterey and Levitus, 1997] that can be altered by optimal interpolation and may have misleading information such as artificial density inversions or false vertical gradients, especially in areas of sparse data [Lozier et al., 1994]. Analyzing individual profiles allows a more detailed and realistic description and thus gives more confidence in the investigation of the physical processes at stake. Unless otherwise indicated, ordinary kriging limited to a $1000-\mathrm{km}$ radius disk containing at least 5 grid point values was used to grid the obtained fields. Kriging is an optimal prediction method very often used in spatial data analysis. It has close links to objective analysis. It is based on statistical principles and on the assumption that the parameter being interpolated can be treated as a regionalized variable, which is true for BLT. One advantage of this geostatistical approach to interpolation is that kriging is an exact interpolator, which does not change any known values. Given the fact that Argo data now offer a very good coverage of the oceans (more than $50 \%$ of the 2 degree grid points are covered in the tropics every month), we can note that different values of the radius of kriging $(500,1000$, or $1500 \mathrm{~km}$ ) barely changes the final fields. Difference between those ones are less than $5 \mathrm{~m}$ everywhere except locally at high latitudes (e.g., in austral ocean during winter).

\subsection{BL Criterion}

[12] In order to characterize the vertical structure of temperature in the upper ocean and to diagnose the top of the oceanic thermocline, we define the depth $D_{T-02}$ where the temperature has decreased by $0.2^{\circ} \mathrm{C}$ as compared to the temperature at the reference depth of $10 \mathrm{~m}$. Although there might be regions and seasons where the temperature (and density) mixed layer is shallower than $10 \mathrm{~m}$ (in areas of strong upwelling in particular), this choice is made in order to have the same reference for all areas and to avoid the diurnal variability of temperature and/or density stratification in the top few meters of the ocean. The threshold $0.2^{\circ} \mathrm{C}$ was diagnosed by de Boyer Montégut et al. [2004] as the most appropriate for mixed layer depth estimation from individual profiles.

[13] Following most previous authors who studied the BL [e.g., Lukas and Lindstrom, 1991; Sprintall and Tomczak, 1992; Vialard and Delecluse, 1998a], we define also the depth $D_{\sigma}$ where the potential density $\sigma_{\theta}$ has increased from the reference depth by a threshold $\Delta \sigma$ equivalent to the density difference for the same temperature change at constant salinity:

$$
\Delta_{\sigma}=\sigma_{\theta}\left(T_{10}-0.2, S_{10}, P_{0}\right)-\sigma_{\theta}\left(T_{10}, S_{10}, P_{0}\right)
$$

where $T_{10}$ and $S_{10}$ are the temperature and salinity at the reference depth $10 \mathrm{~m}$ and $P_{0}$ is the pressure at the ocean surface. Because of oceanic stability, the density is necessarily approximately constant above this depth, which defines thus the base of the density mixed layer. In the idealized situations defined in the introduction where the temperature and density are well mixed until the same depth, then $D_{T-02}=D_{\sigma}$ (slight differences can still be expected in areas where temperature and salinity variations are coupled). However, this is not necessarily the case because of the independence of temperature and salinity and the possible influence of salinity on the upper ocean stability and stratification. As explained in the introduction, the intermediate layer then constitutes the $\mathrm{BL}$ and its thickness is defined as the difference between $D_{T-02}$ and $D_{\sigma}$ (Figure 1). Note that a BL implies constraints both on salinity and temperature stratifications: the former must be well-marked at relatively shallow depth, while the latter must be reached either at a deeper level or must be characterized by a vertical inversion of the thermal gradient, achieved when the temperature reaches a subsurface maximum before the negative threshold (Figure 1).

\section{General Description of the Product 3.1. Global Differences Between Temperature and Salinity Stratification in the Upper Ocean}

[14] Figures 3, 4, and 5 illustrate three major aspects of the global pattern of BLT, defined as $D_{T-02}-D_{\sigma}$ for the purposes of this paper. Namely, Figure 3 shows its seasonal spatial distribution, Figure 4 the thickest BL detected over a seasonal cycle at each grid point and Figure 5 the number of months during which a significant BL is detected. These maps show very clearly that unlike what the past literature on BLs suggest, they are a global phenomenon, which not only concerns the tropics but also higher latitudes. Exception of the midlatitudes $\left(25^{\circ}-45^{\circ}\right)$ must however be underlined, as detailed below. Apart from these latitudinal bands, BLs are thickest in the winter hemisphere (Figure 3), and 

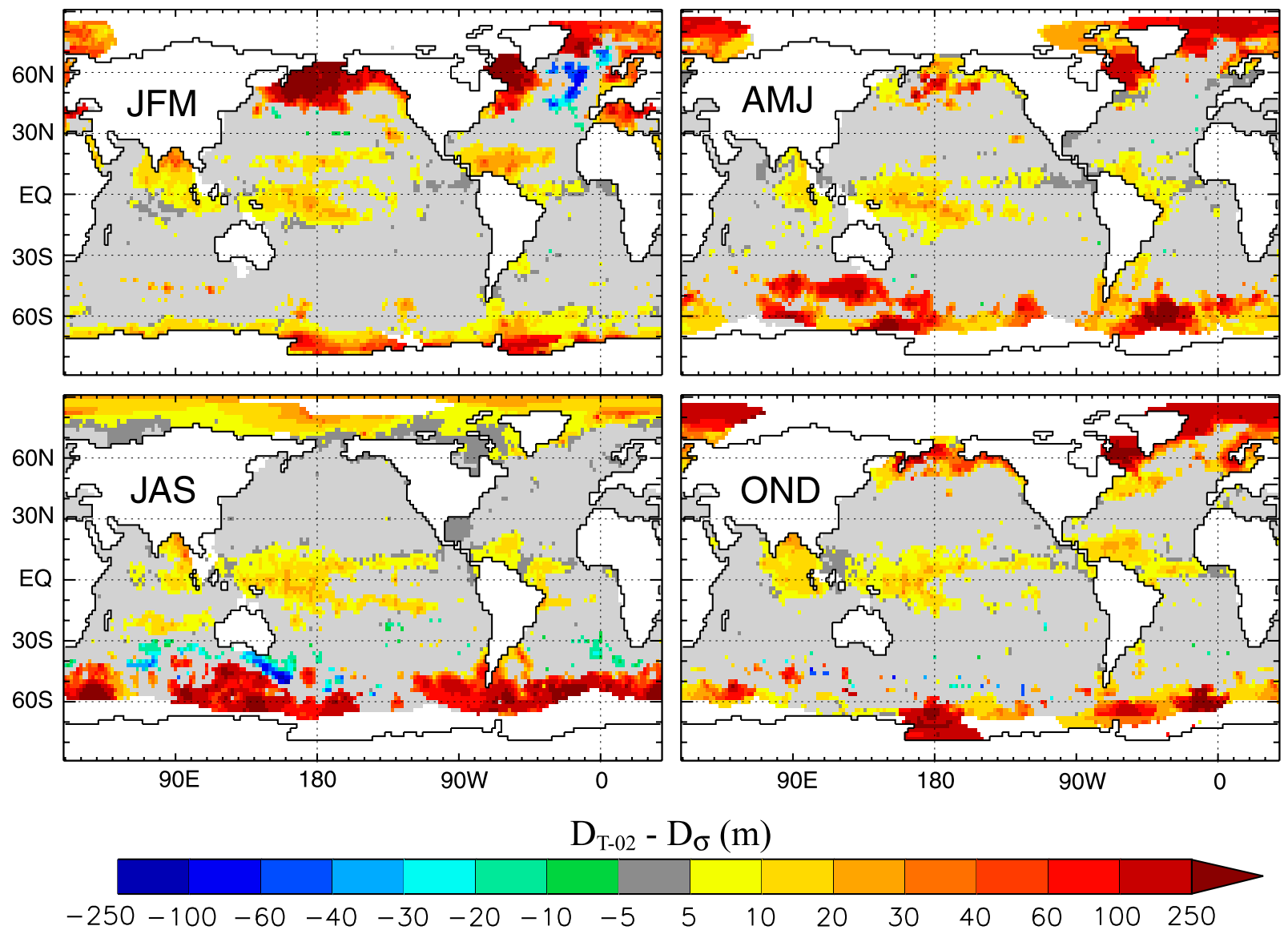

Figure 3. Seasonal maps of the difference between $D_{T-02}$ and $D \sigma$, representing seasonal averages over January to March (JFM), April to June (AMJ), July to September (JAS), and October to December (OND). Positive values correspond to barrier layer thickness (BLT), while negative values corresponds to compensated layer thickness. Data have been kriged every month following de Boyer Montégut et al. [2004]. Grid points where the layer thickness is less than $10 \%$ of the maximal depth $\left(D_{T-02}\right.$ or $\left.D \sigma\right)$ are shown in light grey. White areas represent grid points with no observation or only 1 month observation during the season.

maximum thickness can then exceed $100 \mathrm{~m}$ in the subpolar and polar areas (Figure 4). In the tropical areas, maximum thickness is rather around 40 to $50 \mathrm{~m}$. Note that in these regions, there is a nice spatial correlation between Figure 4 and Figure 5: thickest BLs are the most persistent.

[15] In terms of duration (Figure 5), one can distinguish three types of BL regions: in the equatorial and western tropical Pacific and Atlantic, the Bay of Bengal and eastern equatorial Indian Ocean, the Labrador Sea, and parts of the Arctic and the Southern Ocean, BLs are typically significantly present during at least 10 months per year. They can thus be considered as quasi-permanent. In the Arctic and the Southern Ocean, the lack of data might artificially reduce the extent and length of the BLs detected with the product (see hatches in Figure 5). Seasonal BLs, lasting about 6 months, are detected in the northern subpolar basins, in the Arabian Sea as well as in the southern Indian Ocean, and equatorward of the subtropical salinity maxima, as is described in a companion paper [Mignot et al., 2007]. The third type of area consists in regions where BLs are nearly never detected. They are located around 25 to $45^{\circ}$ latitude in both hemispheres and all basins, as well as along the eastern subtropical oceanic boundaries. Upwellings taking place in the latter areas maintain a very shallow mixed layer and ensure a temperature and salinity stratification down to the same depth.

[16] The equatorial and tropical BLs are easily identified in Figure 3. In the western equatorial Pacific and Atlantic basins and in the eastern equatorial Indian Ocean, BL thickness reaches up to $40 \mathrm{~m}$ and $50 \%$ of the mean mixed layer depth (Figure 4). They are detected almost all months of the year (Figure 5), yet with a seasonal cycle whose amplitude can locally be as high as 30 to $40 \mathrm{~m}$ (Figure 3), especially in the central equatorial Pacific where they are thickest. In the tropics, between 10 and $25^{\circ}$ latitude, differences between $D_{T-02}$ and $D_{\sigma}$ are detected primarily in the autumn and winter seasons of each hemisphere (Figure 3). These BLs reach up to 30 to $50 \mathrm{~m}$ thickness (40 to $60 \%$ of the mean mixed layer depth). They last 5 to 7 months per year in the eastern Atlantic and Pacific basins and often the whole year in the respective western basin. On the contrary, as a result of the specific local geography, the thickest and most long-lasting BLs of the tropical Indian Ocean are detected in the eastern basin (e.g., in the Bay of Bengal). 

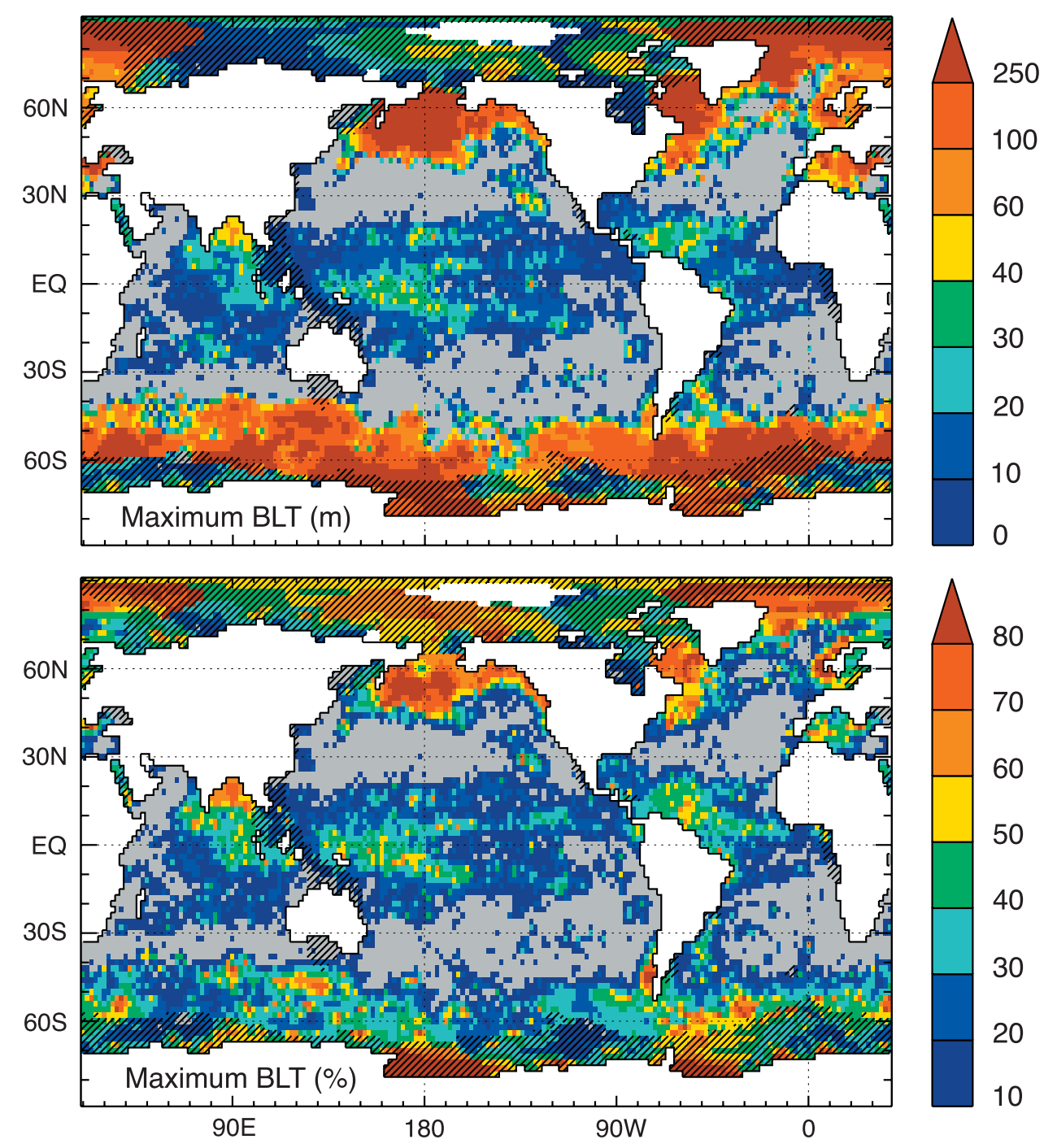

Figure 4. Annual maximum of the monthly barrier layer thickness (BLT), showing (top) the maximum of the BLT in meters and (bottom) the maximum of the BL relative thickness in percentage of the top of the oceanic thermocline depth, as defined here by $D_{T-02}$. Areas where the BL relative thickness never exceeds $10 \%$ over the annual cycle are in light grey. Areas where data are not available over a whole annual cycle are hatched. There, the maximal thickness that we detected thus constitutes a lower limit of what could happen in reality.

A more detailed description of these regions is given by Mignot et al. [2007].

[17] Poleward,in the subtropical gyres (roughly between 25 and $45^{\circ}$ of latitude), the difference $D_{T-02}-D_{\sigma}$ is most often negative, meaning that $D_{\sigma}$ is detected at greater depth than $D_{T-02}$. This implies that the temperature stratification below the well-mixed layer is partially compensated by a stratification in salinity so that the density profile is close to vertical homogeneity on a greater depth than the mixed layer. Overall, BLs can only appear by definition in regions with fresher water in the surface layer than in the subsurface one. Indeed, those compensation regions correspond roughly to decrease of salinity below the mixed layer (not shown). In case of substantial compensation, the corresponding type of mixed layer is described as "vertically compensated" [e.g., Stommel and Fedorov, 1967; de Boyer Montégut et al., 2004]. Such layers are typically detected in the winter season of each hemisphere and they are most prominent in the northeastern Atlantic and in the Southern Ocean (Figure 3). They are also present in the midlatitude basins (Pacific and Atlantic), but they do not reach the $10 \%$ criterion used in Figure 3 and they are thus less visible. Some indications of mechanisms possibly responsible for these compensations are reviewed by de Boyer Montégut et al. [2004], and a detailed analysis will be proposed in a separate study. We concentrate hereafter on situations where $D_{T-02} \geq D_{\sigma}$.

[18] We can note three interesting exceptions in those compensations areas, where significant patterns of BL occur. One is located in the eastern north Pacific around $30^{\circ} \mathrm{N}, 130^{\circ} \mathrm{W}$ and occur in boreal winter and spring. Another one lies in the south Atlantic off shore the widest river in the world, the "Rio de la Plata" (around $35-40^{\circ} \mathrm{S}$, $\left.50^{\circ} \mathrm{W}\right)$. The latter happens to be present all year long with a 


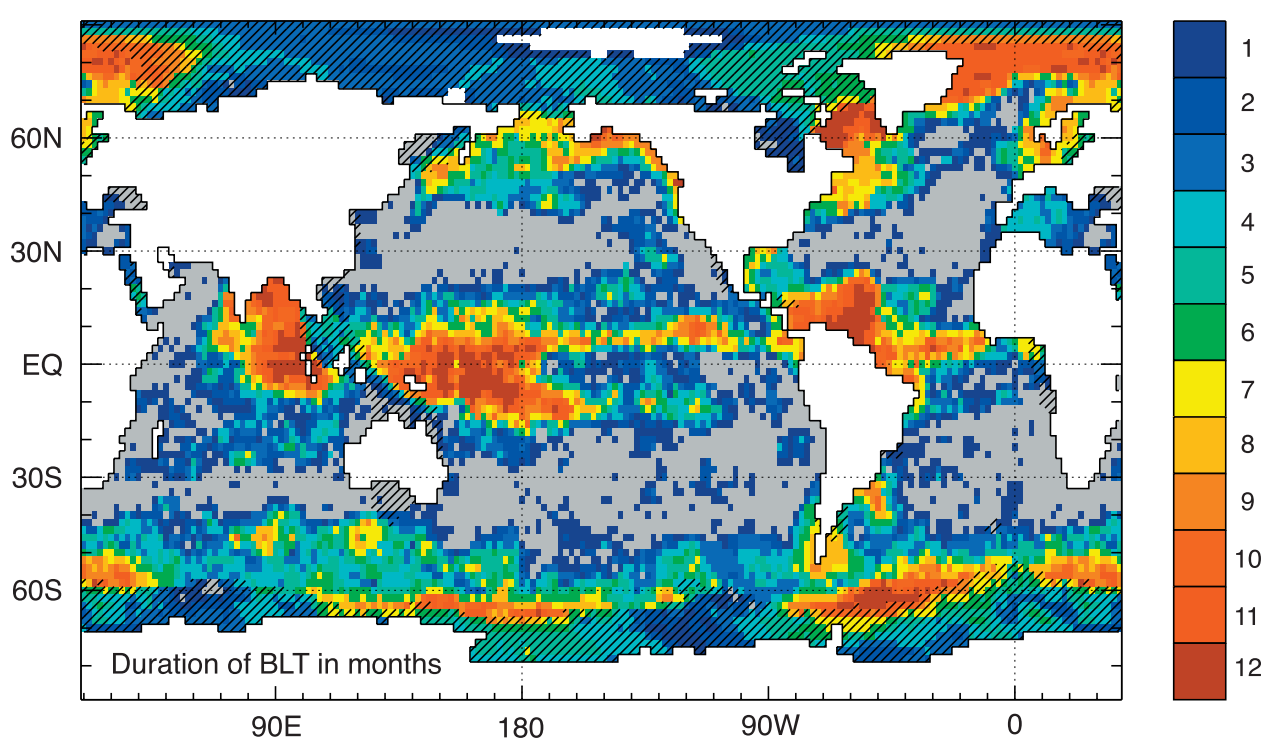

Figure 5. Number of months during which the BL relative thickness (percentage of the BLT relative to the top of the oceanic thermocline depth, as defined here by $D_{T-02}$ ) exceeds $10 \%$. Areas where the BL relative thickness never exceeds $10 \%$ are in light grey. Areas where data are not available over a whole annual cycle are hatched. In these areas, the duration shown constitutes a lower bound of the real duration.

maximum thickness during austral winter. Last, a weaker BL offshore Chile (around $25^{\circ} \mathrm{S}$ ) can be seen in some profiles in November (not shown) and also in Figures 4 and 5. It could present some geographical and seasonal symmetry with the one in eastern north Pacific. To our knowledge, none of them have been previously reported. This latitude band also encompasses the particular case of the Mediterranean Sea where thick BLs develop in the west in winter [D'Ortenzio et al., 2005].

[19] Finally, very large differences between $D_{\sigma}$ and $D_{T-02}$ are detected in the high latitudes of each basin, poleward of $45^{\circ}$. Areas where data are available all year long show a rather strong seasonal cycle amplitude. In winter, the layer between $D_{\sigma}$ and $D_{T-02}$ can locally exceed $500 \mathrm{~m}$ thickness (Figure 4) during more than 3 months in the North Pacific and Labrador Sea (Figures 3 and 5). That is at least as thick as the mixed layer depth itself (Figure 4, bottom). In polar areas the density of the very cold waters is known to be predominantly determined by the salinity while temperature plays a minor role. In these areas, however, the lack of data and the presence of sea-ice during winter make our diagnostics less reliable. In fact, duration and maximal thickness of the BLs shown here constitute a lower bound to reality. BLs in high to polar latitudes are described in more details in section 4 .

\subsection{Temperature Inversions}

[20] As noted above, the fact that the threshold $\Delta T=$ $-0.2^{\circ} \mathrm{C}$ is reached at greater depth than the equivalent density threshold does not necessarily imply that the temperature profile is constant in the intermediate $\mathrm{BL}$ (Figure 1b). Cases of vertical temperature inversions below the mixed layer, where the temperature shows a subsurface maximum below which the threshold $\Delta T=-0.2^{\circ} \mathrm{C}$ is reached, have been reported in the tropical Pacific and
Indian basins in link with BL analysis [e.g., Thadathil and Gosh, 1992; Smyth et al., 1996; Shankar et al., 2004]. As explained by Smyth et al. [1996], the potential climatic impact of such BLs is enhanced, since the subsurface reservoir that can potentially be eroded is even warmer than the sea surface. Furthermore, the vertical processes can even warm the surface layer through turbulent entrainment [Vialard and Delecluse, 1998a; Durand et al., 2004].

[21] Figure 6 confirms the existence of temperature inversions in the Bay of Bengal and southeastern Arabian Sea from December to February [Thadathil and Gosh, 1992; Shankar et al., 2004] and also in the western tropical Pacific [Smyth et al., 1996; Vialard and Delecluse, 1998b]. However, they are not limited to the areas reported above. Instead, they occur in numerous additional regions of the globe, in link with BL phenomenon. Basin-scale subsurface temperature inversions are evidenced in the northern Mediterranean Sea and the northwestern tropical Atlantic, in boreal winter. Inversions can also be seen in eastern equatorial Indian Ocean in boreal summer and in eastern tropical Pacific around $10^{\circ} \mathrm{N}$ in boreal summer and autumn. The subsurface temperature maximum is strongest (more than $1.5^{\circ} \mathrm{C}$ ) at high latitudes, during the local winter season (e.g., Figure 1b). In the Southern Ocean around $50-60^{\circ} \mathrm{S}$, it can appear at more than $200 \mathrm{~m}$ depth, below a mixed layer of about the same depth [e.g., de Boyer Montégut et al., 2004]. In these cold areas, salinity entirely controls the upper ocean stability. Significant inversions are also detected in winter in the subpolar latitudes, namely the Labrador Sea, the northwestern Atlantic and the northern Pacific. They are thickest along the western coast of each basin and their origin will be detailed below (section 4). The BLs located in the northeast subtropical Pacific, in the southwest subtropical Atlantic, and to a smaller extent the one offshore Chile also clearly appear as inversion 
Annual maximal temperature inversions
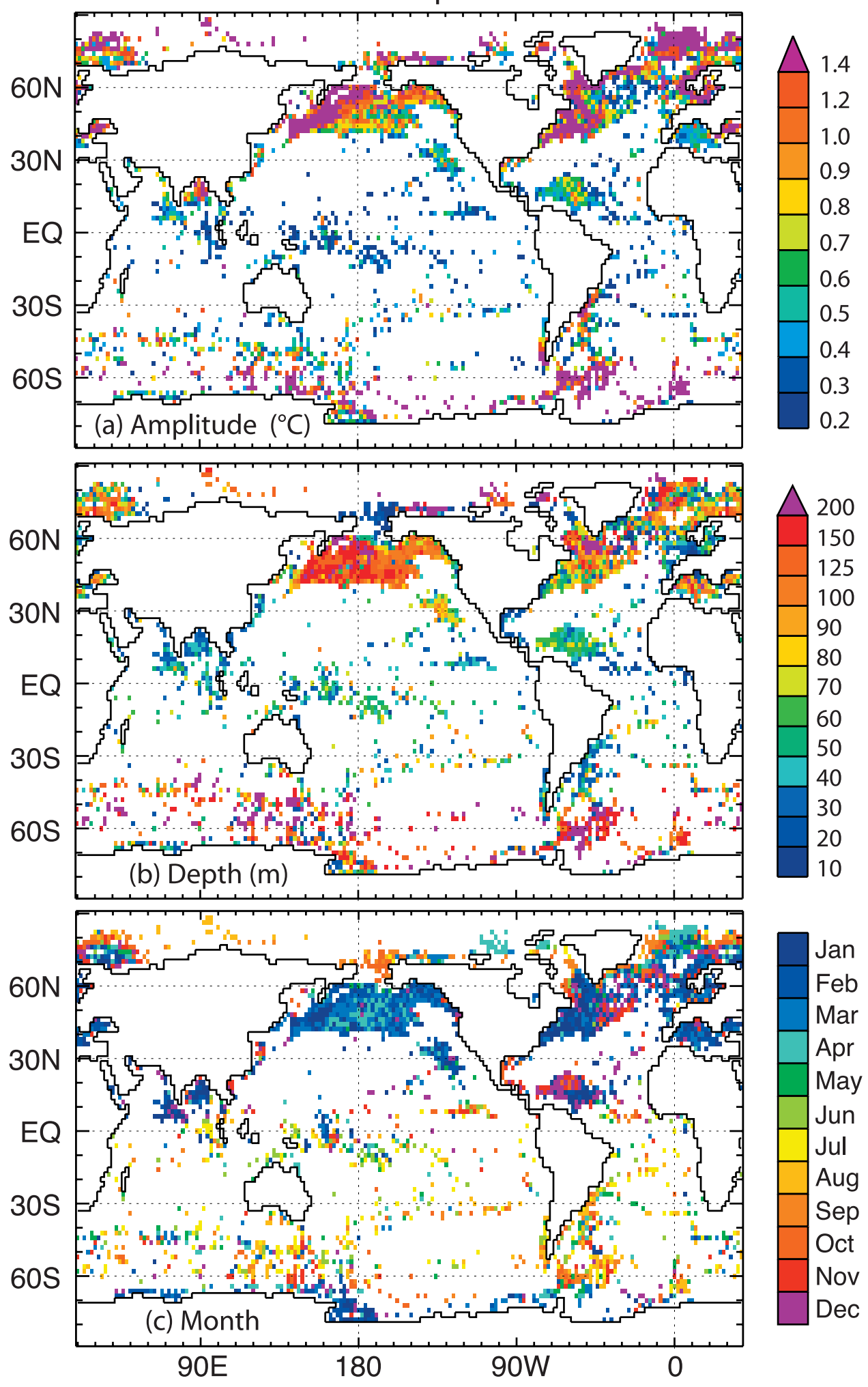

Figure 6. (a) Amplitude, (b) depth, and (c) month of the annual maximal temperature inversions detected in the profiles below the mixed layer. More than 3 million profiles from 1967 to 2006 were used to compute those inversions (see Figure $2 \mathrm{~b}$ ). In order to study reliable inversion patterns, we compute maximal inversions by considering only monthly grid points with at least five available individual profiles and where more than $25 \%$ of those profiles exhibit an inversion of at least $0.2^{\circ} \mathrm{C}$. Note that kriging was not applied to obtain these maps in order to only detect single profiles presenting an inversion. 
regions. As we will see, some of these inversions have already been mentioned in the literature but our product enables the first seasonal and global description of the phenomenon.

[22] This global analysis highlights the close link between vertical temperature inversions and BLs and raises the question of the BL definition. Here, we use the historical definition [e.g., Godfrey and Lindstrom, 1989; Sprintall and Tomczak, 1992; Cronin and McPhaden, 2002], where the tropical BL is viewed as a barrier to turbulent entrainment of cold thermocline water into the surface mixed layer. The BL may therefore constitute a warm subsurface reservoir where increase of temperature occurs as compared to the surface and whose thickness is defined by $D_{T-02}-D_{\sigma}$. Some authors [e.g., Kara et al., 2000; Qu and Meyers, $2005]$ use another definition that consists in comparing $D_{\sigma}$ with $D_{T \pm 02}$. The latter represents the isothermal layer depth, being defined by the depth where the temperature has changed (as opposed to decreased) by $0.2^{\circ} \mathrm{C}$. Both definitions are generally equivalent, except in case of a temperature inversion below the mixed layer (Figure 6). With this second definition, the BLT is then measured as the difference between the inversion depth and the density mixed layer depth. In this paper our aim is to investigate areas of the world ocean where salinity controls the depth of the mixed layer. With the classic definition $\left(D_{T-02}-D_{\sigma}\right)$, in any area where a consistent BL exists, the mixed layer depth is necessarily controlled by the salinity. However, with a definition using the isothermal layer depth $\left(D_{T \pm 02}-D_{\sigma}\right)$, $\mathrm{BL}$ areas with temperature inversions at the base of the mixed layer (e.g., Bay of Bengal in January, north Pacific and Labrador Sea in winter) are not detected, whereas salinity does control the depth of the mixed layer and the water column stability. We therefore choose to apply the classic definition to the global ocean. While being consistent with $\mathrm{BL}$ definition in the tropics, we can call by extension a $\mathrm{BL}$ the layer between $D_{T-02}$ and $D_{\sigma}$, whose thickness gives us regions of the world where salinity controls the mixed layer depth and allows for a shallower pycnocline.

[23] Thanks to the recent Argo data, new global monthly maps of BLT can now be constructed and investigated as has been done in that section. The data coverage and density has especially been considerably improved, yielding more reliable fields. As indicated in the introduction, tropical BLs have already been quite extensively studied in several papers, most of them using local high-resolution data sets [e.g., Ando and McPhaden, 1997; Cronin and McPhaden, 2002]. Such tropical BLs are fundamental since they have a potential climatic impact through their role in air-sea interactions. The companion paper [Mignot et al., 2007] therefore focuses on the tropical areas to give a more elaborate analysis of those important BLs. Here, we also exhibited the widespread occurrence of BLs in high latitudes. Those areas have not been as extensively explored in a BL perspective. In the following section we will describe and discuss more thoroughly BLs in the subpolar and polar regions.

\section{Subpolar and Polar Regions}

[24] Important differences between $D_{T-02}$ and $D_{\sigma}$ are clearly detected in the subpolar and polar areas (e.g.,
Figure 4). In the North Pacific middle to high latitudes in particular, they can exceed $500 \mathrm{~m}$ in winter (Figure 3), which is close to $100 \%$ of what is defined here as the top of the oceanic thermocline depth, $D_{T-02}$ (Figure 4$)$. This is due to the fact that strong temperature inversions of $0.5^{\circ} \mathrm{C}$ or more can occur there in winter (e.g., Figure 1b). In those areas, sea surface temperature can get much colder than in the subsurface while salinity controls the stability of the upper ocean. BLs of similar thickness are also present in the North Atlantic, along the western coast. They extend to the Labrador Sea where they are particularly long lasting (Figure 5). In this section, we will also investigate the thick BLs detected in the Arctic and Southern oceans, in spite of a lack of data.

\subsection{North Pacific}

[25] Thick BLs in the north Pacific have been reported previously by Monterey and Levitus [1997] and were further documented by Kara et al. [2000]. According to our product, they can be as thick as $500 \mathrm{~m}$ (Figure 4) in winter. This is much more than the $50 \mathrm{~m}$ indicated by Kara et al. [2000], and the difference is due to a different definition of $D_{T}$ as explained at the end of section 3.2. Using the same BL definition as in the work of Kara et al. [2000], we find BLs of about $20 \mathrm{~m}$ thickness in the north Pacific during winter (see for example the profile on Figure 1b).

[26] Kara et al. [2000] attributed the formation of BLs in these areas to the combined effect of oceanic surface heat loss in winter that deepen the seasonal temperature stratification and persistent precipitations that induce a shallow halocline maintained by the upward Ekman suction of the subpolar gyre. However, this interpretation may be misleading in the case of the strong vertical temperature inversions detected in the North Pacific subarctic region (Figure 6). Those ones are around 200 (in the west) and 100 (in the east) $\mathrm{m}$ depth and were already noted in several studies [e.g., Uda, 1963; Ueno and Yasuda, 2000]. Kara et al.'s [2000] view implies that temperature has been mixed by surface cooling until a depth about $50 \mathrm{~m}$ below the salinity stratification. This is not supported by the strong inversions of temperature that we report above and which occur roughly at the same depth as the salinity and density stratification (e.g., Figure 1b). Thus we rather propose that the intense precipitations inhibit deep vertical mixing while the Ekman suction contributes to maintain the shallow halocline. This prevents the deepening of the thermocline in winter and subsurface waters are protected from the surface cooling. They remain relatively warm and together with winter surface cooling, this can give rise to the observed vertical temperature inversions. Differences between $D_{T-02}$ and $D_{\sigma}$ vanish during the warm season (Figures 3 and 5), when atmospheric heat fluxes induce a shallow seasonal thermocline that coincides with $D_{\sigma}$.

[27] Using isopycnal simulations, Endoh et al. [2004] recently highlighted the importance of horizontal advection of warm and saline Kuroshio waters to maintain the vertical temperature inversion together with the salinity stratification, in the western part of the subarctic basin in particular. Similarly, Cokelet and Stabeno [1997] proposed that further north, in the Aleutian Basin, the deep subsurface temperature maximum is maintained by lateral inflow of warm Alaskan Stream water through the passes of the 
Aleutian Basin. Beside that basin, the eastern North Pacific winter BL might be linked with the formation of eastern North Pacific Subtropical Mode Waters, which is subject to strong interannual variability compared to other mode waters. More analysis is needed to quantify the respective role of the local and the advective mechanism. Note yet that in both cases, the Ekman suction of the subpolar gyre plays an important role in maintaining the halocline and the vertical temperature inversion. Note also that Wirts and Johnson [2005] recently reported that the subsurface temperature inversion of the southeast Aleutian Basin had decreased during the last winters due to a combination of atypical ocean advection and anomalous atmospheric forcing. This should correspond to modifications of the BL pattern.

\subsection{North Atlantic}

[28] Thick BLs in the western Atlantic midlatitudes (40$55^{\circ} \mathrm{N}$ ) have never been mentioned or described to our knowledge. They are confined to the shelfbreak of the Middle Atlantic Bight, along the eastern American coast south of Newfoundland (Figure 3). The situation looks very similar to its Pacific counterpart, although the BLs are quite thinner (up to about $100 \mathrm{~m}$, Figures 3 and 4, top) and they do not extend eastward across the basin. Inversions are also present but they are shallower (Figure 6). They are even as shallow as 20 to $40 \mathrm{~m}$ in the south of the area, in a small zone north of Cape Hatteras, consistent with Linder and Gawarkiewicz's [1998] findings.

[29] The area along the American coast, following the path of the Gulf Stream, constitutes a boundary between the cool, fresh continental shelf water mass and the warm, saline so-called "upper slope water pycnostad" [Wright and Parker, 1976; Linder and Gawarkiewicz, 1998] below, which results from the complex interaction of the Gulf Stream with local waters [e.g., Pickart et al., 1999]. This superposition of different water masses is the origin of the inversed vertical temperature profiles (Figure 6), which are here again partly maintained by upward Ekman pumping (not shown) and the positive buoyancy flux inhibiting vertical mixing. The high SSS values of the North Atlantic and its specific circulation are probably the reason why the BL does not extends eastward as much as in the Pacific.

[30] It is not clear whether similar BLs are present also in the Southern Hemisphere. A BL of about $30 \mathrm{~m}$ thickness is present in austral winter (July to September) in the western South Atlantic $\left(35^{\circ} \mathrm{S}-50^{\circ} \mathrm{W}\right.$, Figure 3). It also presents a significant temperature inversion (Figure 6) and could thus be symmetrical to the ones detected in the Northern Hemisphere. No equivalent is yet detected in the other basins.

\subsection{Arctic Ocean and Nordic and Labrador Seas}

[31] In the Arctic ocean the surface mixed layer is very fresh, as a result of precipitation and abundant river discharges [e.g., Aagaard and Carmack, 1989], with a temperature virtually at the freezing point. The water mass that lies below consists of warm and salty Atlantic waters that enter the Eurasian Basin through Fram Strait and across the Barents Sea [e.g., Rudels et al., 1996; Morison et al., 1998]. In all seasons but summer, a strong halocline thus defines $D_{\sigma}$ while below, the temperature profile is again typically unstable, as shown in Figure 6. Note that this halocline is relatively thick and influenced, among other, by the seasonal inflow of relatively fresh Pacific waters through Bering Strait [e.g., Woodgate et al., 2005]. In summer, atmospheric heating over open water and leads induces a shallow seasonal thermocline that limits the warmed mixed layer. The difference in density and temperature stratification is thus strongly reduced (Figure 3, compare JAS and OND). Lack of data might however introduce biases in the results in this area.

[32] The winter situation in the Baltic Sea, where warm and salty waters from the Atlantic penetrate through irregular pulses under the fresh surface layer, resulting in a sharp permanent halocline around 50 to $80 \mathrm{~m}$ depth [e.g., Meier, 2001], is similar to the Arctic Ocean. In summer, atmospheric heating is such that no more stratification is detected by our criteria. In the Labrador and Nordic Seas, as well as in the Bering Sea, the winter vertical stratification is very similar to that of the Arctic ocean and temperature inversions are also present (Figure 6).

\subsection{Austral Ocean}

[33] Thickest differences between $D_{T-02}$ and $D_{\sigma}$ are finally detected in the Austral Ocean southward of the polar front (about $54^{\circ} \mathrm{S}$ ) in austral winter (Figure 3 and 4). They are also associated to the largest and deepest vertical temperature inversions (Figure 6). The deep and cold layer of Winter Water is indeed overlying the warmer and saltier Upper Circumpolar Deep Water [e.g., Rintoul et al., 2001] inducing a situation symmetrical to that of the extreme north. From the analysis of several sections between Tasmania and Antarctica, Chaigneau et al. [2004] confirmed that the salinity maintains the stability of the water column which would otherwise be destabilized by a $3^{\circ} \mathrm{C}$ temperature drop across the mixed layer. In summer the warmer Antarctic Surface Water defines a shallow thermocline that limits the mixed layer depth [Chaigneau et al., 2004]. $D_{\sigma}$ and $D_{T-02}$ are then equal.

\section{Conclusions}

[34] We have presented and analyzed a new climatology of the differences between temperature and density stratification in the upper ocean highlighting the influence of salinity on this stratification. The product is based on the compilation of the recent NODC, WOCE, and Argo databases. The use of the latter in particular represents a substantive improvement with respect to de Boyer Montégut et al.'s [2004] preliminary results in terms of $\mathrm{BL}$ analysis. It leads to a considerable increase in data coverage and density, representing 30\% of the total profiles of the data. The main novelty of our climatology as compared to previous global and large-scale studies is that it is based on profile-wise computations. This results in more realistic and detailed structures than already gridded profiles, since no merging by smoothing or interpolation is applied.

[35] Generally, the analysis has confirmed that the classic picture of temperature and salinity being mixed over the same depth is highly simplified. In the real ocean the situation is very often different. Quasi-permanent (1012 months) BLs are observed in the equatorial and western tropical Pacific and Atlantic, in the Bay of Bengal and the eastern equatorial Indian Ocean, in the Labrador Sea, and 
parts of the Arctic and Southern Ocean. In the northern Atlantic and Pacific subpolar basins, in the southern Indian Ocean, in the Arabian Sea, and equatorward of the subtropical Atlantic and Pacific salinity maxima, BLs are rather seasonal, lasting about 6 months per year. BLs are finally almost never detected around $30-40^{\circ}$ of latitude in each basin and in tropical and subtropical coastal upwelling regions, where mixed layers are extremely shallow. One important exception is, however, the BL in the Java and Sumatra area which has been extensively studied by Masson et al. [2002] and Qu and Meyers [2005].

[36] These BLs patterns are often associated with temperature inversions below the homogeneous surface layer. The latter may exist since salinity controls the stratification and water column stability in the upper ocean. Such inversions occur in several regions of the globe. In the tropics the most striking ones are in the Bay of Bengal and southeastern Arabian Sea in winter, in the west tropical Pacific, in the east equatorial Indian Ocean, and a large pattern in the northwestern tropical Atlantic during winter. Temperature inversions are maximum in amplitude and depth (reaching more than $1.5^{\circ} \mathrm{C}$ at depth over $100 \mathrm{~m}$ ) in high latitudes in winter (e.g., north Pacific, Southern Ocean, Labrador Sea).

[37] Poleward of about $45^{\circ} \mathrm{N}$ and $\mathrm{S}$, winter vertical temperature profiles are very often inversed, i.e., the temperature is maximum below the mixed layer, around 100 to more than $200 \mathrm{~m}$ depth (austral Ocean). Inversions are particularly deep and strong along the eastern coast, in the Kuroshio (Pacific) and Gulf Stream (Atlantic) path. This results in thick (up to about $500 \mathrm{~m}$ in the northwestern Pacific) differences between $D_{\sigma}$ and $D_{T-02}$ in the North Pacific and western Atlantic in winter. These differences have already been reported recently [Kara et al., 2000], but the characteristic temperature inversions was not discussed.

[38] That phenomenon enabled us to propose a slightly different formation mechanism than the one proposed by these authors. It implies the formation of a persistent halocline by intense precipitation, partly maintained by Ekman succion, that prevents the surface cooling to penetrate at depth. Moreover, regarding the temperature inversion, subsurface advection by the western boundary current and their open ocean drift of warmer and saltier water than the surface might also contribute to the observed structure in both basins. Note that while these BLs are located across the whole basin in the Pacific, they are slightly thinner and rather confined to the western basin in the Atlantic. Maximum temperature inversions are also shallower.

[39] In the Southern Ocean, the maximal subsurface temperature inversion can exceed $1.5^{\circ} \mathrm{C}$ compared to the surface and be reached around $250 \mathrm{~m}$ depth. Generally, in the polar areas, the density and the stability of the upper ocean are primarily controlled by the salinity. The temperature inversions are due to the presence of a very fresh and relatively cold surface layer that lies above a warmer and saltier water mass advected from equatorward areas. Cold winter atmospheric fluxes but also intense input of freshwater from the atmospheric precipitations (Arctic and southern oceans) or river runoff (Arctic ocean) thus play a major role in setting this vertical structure. In summer the seasonal thermocline resulting from surface heating generally limits the mixed layer depth, and the BL disappears.
The latter can however persist several months in areas that are still covered with ice (open Arctic ocean) and in areas where very fresh surface waters induced by sea ice melting in late winter-early spring prevent the warming of the subsurface waters (Labrador and Nordic Seas, area of the Bering Strait).

[40] Our concern was not to assess each BL formation mechanism in details. We believe that this should be done ultimately by different groups, focusing on specific areas. The present analysis suggests that these mechanisms are various and often not simple, implying atmospheric freshwater and heat forcing, advection, and runoff. Yet, a symmetry in terms of BL occurrence, seasonality, and formation mechanism has been revealed for the subpolar North Pacific and western Atlantic and for the polar regions. The companion paper [Mignot et al., 2007] shows that this holds also for the BLs located immediately equatorward of the salinity subtropical maximum. Finally this north-south hemispheres symmetry appears to be true at any latitude away from the deep tropics.

[41] Our global analysis has provided some new understanding of the BL formation mechanism in areas such as the northern Atlantic and Pacific basin. However, the differences between the northern Atlantic and Pacific oceans has to be investigated in greater details together with the quantification of the advective versus the local mechanism.

[42] Finally, the origin of BLs detected in the $25-45^{\circ}$ latitude zone (offshore California, Rio de la Plata, and Chile) and associated to vertical temperature inversions were not explained. To our knowledge, it is not referred in the literature, but it corresponds to a well covered area and should thus be robust. Future work should be dedicated to their understanding.

[43] We also detected significant large-scale areas where a vertical compensation between salinity and temperature stratification occurs. They seem to be detected primarily in winter and in the midlatitudes of each basins and their thickness is significant in comparison to the mixed layer depth in the southern ocean, equatorward of the subpolar front, and in the North Atlantic. They will be investigated in details in a forthcoming study.

[44] The structures and orders of magnitude that we detected are overall in agreement with previous large-scale studies [Sprintall and Tomczak, 1992; Tomczak and Godfrey, 1994; Monterey and Levitus, 1997] and more detailed local studies (several references in the text). We believe that the data set would be useful for a large spectrum of oceanographic studies such as the revision of accurate upper ocean heat, salt, and biological budgets, and the validation of ocean general circulation models. In several regions, mechanisms of BL formation and destruction are indeed still poorly understood. Owing to the lack of data, their investigation requires the use of ocean general circulation models, that need to be validated against a reliable and robust product [e.g., Durand et al., 2007]. For these reasons, we would like to make our product public. The monthly mean differences $D_{T-02}-D_{\sigma}$ as well as the fields $D_{T-02}$ and $D_{\sigma}$ themselves can be downloaded from http:/www.locean-ipsl.upmc.fr/ $\sim$ cdblod/blt.html.

[45] Acknowledgments. We would like to acknowledge the National Oceanographic Data Center, the World Ocean Circulation Experiment, and 
the Coriolis project for the rich publicly available databases. We are grateful to Gilles Reverdin for stimulating discussions, constructive comments, and encouragements and to Fabien Durand and Roger Lukas for detailed comments on the manuscript. We also thank the anonymous reviewers for their constructive comments that lead to the improvements of the manuscript. CBM was partly supported by a DGA grant (DGA-CNRS 2001292) and by fundings of the Programme National d'Etude de la Dynamique et du Climat (PNEDC).

\section{References}

Aagaard, K., and E. Carmack (1989), The role of sea ice and other fresh water in the arctic circulation, J. Geophys. Res., 94, 14,485-14,497.

Ando, K., and M. J. McPhaden (1997), Variability of surface layer hydrography in the tropical Pacific Ocean, J. Geophys. Res., 102, 23,063-23,078.

Chaigneau, A., R. A. Morrow, and S. R. Rintoul (2004), Seasonal and interannual evolution of the mixed layer in the Antarctic Zone south of Tasmania, Deep Sea Res. I, 51, 2047-2072.

Cokelet, E. D., and P. J. Stabeno (1997), Mooring, observations of the thermal structure, salinity and currents in the SE Bering Sea basin, J. Geophys. Res., 102, 22,947-22,964.

Cronin, M. F., and M. J. McPhaden (2002), Barrier layer formation during westerly wind bursts, J. Geophys. Res., 107(C12), 8020, doi:10.1029/ 2001JC001171.

de Boyer Montégut, C., G. Madec, A. S. Fisher, A. Lazar, and D. Iudicone (2004), Mixed layer depth over the global ocean: an examination of profile data and a profile-based climatology, J. Geophys. Res., 109, C12003, doi:10.1029/2004JC002378.

Defant, A. (1961), Physical Oceanography, vol. 1, 729 pp., Pergamon, London.

D’Ortenzio, F., D. Iudicone, C. de Boyer Montégut, P. Testor, D. Antoine, S. Marullo, R. Santoleri, and G. Madec (2005), Seasonal variability of the mixed layer depth in the Mediterranean Sea as derived from in situ profiles, Geophys. Res. Lett., 32, L12605, doi:10.1029/2005GL022463.

Durand, F., S. R. Shetye, J. Vialard, D. Shankar, S. S. C. Shenoi, C. Ethe, and G. Madec (2004), Impact of temperature inversion on SST evolution in the South-Eastern Arabian Sea during the pre-summer monsoon season, Geophys. Res. Lett., 31, L01305, doi:10.1029/2003GL018906.

Durand, F., D. Shankar, C. de Boyer Montégut, S. S. C. Shenoi, B. Blanke, and G. Madec (2007), Modeling the barrier-layer formation in the SouthEastern Arabian Sea, J. Clim, 20, 2109-2120.

Endoh, T., H. Mitsudera, S.-P. Xie, and B. Qiu (2004), Thermohaline structure in the subarctic North Pacific simulated in a general circulation model, J. Phys. Oceanogr., 34, 360-371.

Godfrey, J. S., and E. J. Lindstrom (1989), The heat budget of the equatorial western Pacific surface mixed layer, J. Geophys. Res., 94, 8007-8017.

Kara, A. B., P. A. Rochford, and H. E. Hulburt (2000), Mixed layer depth variability and barrier layer formation over the North Pacific Ocean, J. Geophys. Res., 105, 16,803-16,821.

Levitus, S. (1982), Climatological atlas of the world ocean, tech. rep. 13, NOAA, Rockville, Md.

Levitus, S., and T. Boyer (1994), Temperature, vol. 4, World Ocean Atlas, 117 pp., NOAA, Washington D. C.

Lindstrom, E., R. Lukas, R. Fine, E. Firing, S. Godfrey, G. Meyers, and M. Tsuchiya (1987), The Western Equatorial Pacific Ocean Circulation Study, Nature, 300, 533-537.

Linder, C. A., and G. Gawarkiewicz (1998), A climatology of the shelfbreak front in the Middle Atlantic Bight, J. Geophys. Res., 103, $18,405-18,423$.

Lozier, M. S., M. S. McCartney, and W. B. Owens (1994), Anomalous anomalies in averaged hydrographic data, J. Phys. Oceanogr., 24, 2624-2638

Lukas, R., and E. Lindstrom (1987), The mixed layer of the western equatorial Pacific Ocean, paper presented at 'Aha Huliko'a Hawaiian Winter Workshop on the Dynamics of the Oceanic Surface Mixed Layer, Hawaii Inst. of Geophys., Honolulu.

Lukas, R., and E. Lindstrom (1991), The mixed layer of the western equatorial Pacific Ocean, J. Geophys. Res., 96, 3343-3357.

Maes, C., J. Picaut, and S. Belamari (2002), Salinity barrier layer and onset of El Niño in a Pacific coupled model, Geophys. Res. Lett., 29(24), 2206, doi:10.1029/2002GL016029.

Maes, C., J. Picaut, A. Kentaro, and K. Yoshifumi (2004), Characteristics of the convergence zone at the eastern edge of the Pacific warm pool, Geophys. Res. Lett., 31, L11304, doi:10.1029/2004GL019867.

Masson, S., P. Delecluse, J.-P. Boulager, and C. Menkes (2002), A model study of the seasonal variability and formation mechanisms of the barrier layer in the equatorial Indian Ocean, J. Geophys. Res., 107(C12), 8017, doi:10.1029/2001JC000832.

Masson, S., J.-J. Luo, G. Madec, J. Vialard, F. Durand, S. Gualdi, E. Guilyardi, S. Behera, P. Delecluse, A. Navarra, and P. Yamagata (2005), Impact of barrier layer on winterspring variability of the southeastern Arabian Sea, Geophys. Res. Lett., 32, L07703, doi:10.1029/2004GL021980.

Meier, H. E. M. (2001), On the parameterization of mixing in 3D Baltic Sea models, J. Geophys. Res., 106, 30,997-31,016.

Mignot, J., C. de Boyer Montégut, A. Lazar, and S. Cravatte (2007), Control of salinity on the mixed layer depth in the world ocean: 2. Tropical areas, J. Geophys. Res, doi:10.1029/2006JC003954, in press. Monterey, G., and S. Levitus (1997), Seasonnal variability of mixed layer depth for the world ocean, technical report, NOAA, Silver Spring, Md.

Morison, J., M. Steele, and R. Anderson (1998), Hydrography of the upper Arctic Ocean measured from the nuclear submarine USS Pargo, Deep Sea Res. I, 45, 15-38.

Pickart, R. S., T. K. McKee, D. J. Torres, and S. A. Harrington (1999), Mean structure and variability of the slopewater system south of Newfoundland, J. Phys. Oceanogr., 29, 2541-2558.

Qu, T., and G. Meyers (2005), Seasonal variation of barrier layer in the southeastern tropical Indian Ocean, J. Geophys. Res., 110, C11003, doi:10.1029/2004JC002816.

Reverdin, G., D. Cayan, and Y. Kushnir (1997), Decadal variability of hydrography in the upper northern North Atlantic in 1948-1990, J. Geophys. Res., 102, 8505-8531.

Rintoul, S. R., C. W. Hughes, and D. Olbers (2001), The Antarctic Circumpolar Current system, in Ocean Circulation and Climate, edited by G. Siedler, W. J. Gould, and J. Church, pp. 271-301, Academic, New York. Rotschi, H., P. Hisard, and F. Jarrige (1972), Les eaux du Pacifique occidental à $170 \mathrm{E}$ entre $20 \mathrm{~S}$ et $4 \mathrm{~N}$, technical report, Inst. de Rech. pour le Dev., Paris. Rudels, B., L. G. Anderson, and E. P. Jones (1996), Formation and evolution of the surface mixed layer and halocline of the Arctic Ocean, J. Geophys. Res., 101, 8807-8821.

Sato, K., T. Suga, and K. Hanawa (2004), Barrier layer in the North Pacific subtropical gyre, Geophys. Res. Lett., 31, L05301, doi:10.1029/ 2003GL018590.

Shankar, D., V. V. Gopalakrishna, S. S. C. Shenoi, F. Durand, S. R. Shetye, C. K. Rajan, Z. Johnson, N. Araligidad, and G. S. Michael (2004), Observational evidence for westward propagation of temperature inversion in the southeastern Arabian Sea, Geophys. Res. Lett., 31, L08305, doi:10.1029/2004GL019652.

Smyth, W. D., D. Hebert, and J. N. Moum (1996), Local ocean response to a multiphase westerly wind burst: 2 . Thermal and freshwater responses, J. Geophys. Res., 101, 22,513-22,534.

Sprintall, J., and M. Tomczak (1992), Evidence of the barrier layer in the surface layer of the Tropics, J. Geophys. Res., 97, 7305-7316.

Stommel, H., and K. N. Fedorov (1967), Small scale structure in temperature and salinity near Timor and Mindanao, Tellus, 19, 306-325.

Thadathil, P., and A. K. Gosh (1992), Surface layer temperature inversion in the Arabian Sea during winter, J. Oceanogr., 48, 293-304.

Tomczak, M., and J. S. Godfrey (1994), Regional Oceanography: An Introduction, Pergamon, New York. (Avalaible at http://www.cmima. csic.es/mirror/mattom/regoc/pdfversion.html)

Uda, M. (1963), Oceanography of the Subarctic Pacific Ocean, J. Fish. Res. Board Can., 20, 119-179.

Ueno, H., and I. Yasuda (2000), Distribution and formation of the mesothermal structure (temperture inversions) in the North Pacific subarctic region, J. Geophys. Res., 105, 16,885-16,897.

Vialard, J., and P. Delecluse (1998a), An OGCM study for the TOGA decade. part 1: role of salinity in the physics of the western Pacific fresh pool, J. Phys. Oceanogr., 28, 1071-1088.

Vialard, J., and P. Delecluse (1998b), An OGCM study for the TOGA decade. part 2: barrier-layer formation and variability, J. Phys. Oceanogr., $28,1089-1106$

Wirts, A. E., and G. C. Johnson (2005), Recent interannual upper ocean variability in the deep southeastern Bering Sea, J. Mar. Res., 63, 381-405. Woodgate, R. A., K. Aagaard, and T. J. Weingartner (2005), Monthly temperature, salinity, and transport variability of the Bering Strait through flow, Geophys. Res. Lett., 32, L04601, doi:10.1029/2004GL021880.

Wright, W. R., and C. E. Parker (1976), A volumetric temperature/salinity census for the Middle Atlantic Bight, Limnol. Oceanogr., 21, 563-571.

S. Cravatte, Laboratoire d'Etudes en Géophysique et Océanographie Spatiales, Unité Mixte de Recherche, CNRS/IRD/CNES/Université Paul Sabatier, 14, av. Edouard Belin, F-31400 Toulouse, France.

A. Lazar and J. Mignot, Laboratoire d'Océanographie et du Climat: Expérimentations et Approches Numériques, Institut Pierre Simon Laplace, Unité Mixte de Recherche, CNRS/IRD/UPMC, 4 place Jussieu, Case 100, F-75252 Paris, France.

C. de Boyer Montégut, Frontier Research Center for Global Change, Japan Agency for Marine-Earth Science and Technology, 3173-25 Showamachi, Kanazawa-ku, Yokohama, Kanagawa 236-0001 Japan. 